\title{
Modeling Various Teaching Methods In A Faculty Of Education In Science Education: Chalk And Talk, Virtual Labs Or Hovercrafts
}

\author{
Gerald Laronde, Nipissing University, Canada \\ Katarin MacLeod, St. Francis Xavier University, Canada
}

\begin{abstract}
This research was conducted with 291 Junior/Intermediate (J/I) pre-service teachers in a ubiquitous laptop Bachelor of Education program at Nipissing University. The authors modeled a lesson using three different teaching styles using flight as the content medium, a specific expectation found in the Ontario Ministry of Education grade six Science curriculum (Ontario Ministry of Education, 1998). The three parts of the lesson were entitled: 1) "Chalk and Talk", which followed a traditional teacher directed teaching style, 2) "A Virtual Lab" where pre-service teachers gather information about flight via an online website from their laptops, and 3) "A Hovercraft Lesson" which engaged the pre-service teachers in four learning stations about hovercrafts, one of which was to experience riding a home-made hovercraft from plywood and a leaf blower. The pre-service teachers participated in the lessons and then completed an online survey that enabled the rating each of the lessons for strengths and weaknesses, engagement, and their motivation toward the topic. Pre-service teachers rated and commented about the lessons in regard to teaching preference, preparation time, and perceived student engagement within a school setting. The online survey gathered both quantitative and qualitative data. The survey informed the authors on the type of learning and teaching style the pre-service teachers preferred and why. It also provided information on the advantages and disadvantages of the three different teaching styles as perceived by the pre-service teachers. Analysis indicates that the pre-service teachers preferred the Hovercraft lesson regardless of the preparation time required or the safety hazards. Previous research indicates that pre-service teachers tend to teach in a style in the classroom as they were taught in a Faculty of Education; therefore, modeling and analyzing various teaching methods is an important component of teacher education.
\end{abstract}

Keywords: Pre-Service Teacher; Teacher Education; Science Education; Teaching Methods; Constructivism; Experiential Education

\section{INTRODUCTION}

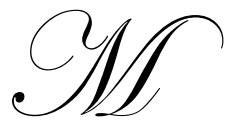

odeling different teaching styles in a Faculty of Education is an effective method of pedagogy in that pre-service teachers are more likely to practice similar learned methods in their own teaching in the classroom (Lortie, 1975). Experiential learning and recognizing the different learning styles of individuals (Kolb, 1984, and Carver, 1994) has been a part of learning theory in many Faculties of Education since the 1980 's. For teachers to reach as many students as possible, a variety of teaching styles should be used to meet these various learning styles (Felder, 1993). Although there has been debate among psychologists and academics on the scientific basis for learning styles (Curry, 1990, and Pashler et al., 2009), a variety of teaching methods can be considered beneficial for both the teacher and learner. 


\section{METHODOLOGY}

This is a mixed methods research project and incorporates both quantitative and qualitative data from using a case study model based in the research by Yin and described by Creswell (Creswell, 2007).The authors designed three different styles of mini lessons on the Ontario Ministry of Education curriculum grade 6 Science topic - flight - which were taught during a two-hour instructional block as part of the Junior/Intermediate (J/I) Science course in the Bachelor of Education at Nipissing University. After the lesson, the pre-service teachers completed an anonymous online survey, using surveyconsole.com, evaluating each of the mini lessons using a Likert scale in regard to their own learning, their active participation, their level of engagement, their familiarity with the teaching style, and if they thought that a typical grade 6 class would find the lesson engaging. They also were asked to describe the advantages and disadvantages in preparation and implementation of each style of lesson, what changes they would make to the lesson to fit their teaching style, and which style of lesson they would prefer to teach in their own classroom.

The three lessons were crafted to fit into three different teaching styles with varying degrees of constructivism. Although it is difficult to classify a lesson solely toward one particular teaching style, the mini lessons were classified using Miller's (1990) three general teaching approaches - transmission, transaction and transformation. Constructivism can be considered a theory (Matthews, 2008), but in the context of this study, it was considered as the relative amount of hands-on activity - or interaction - that occurred within the pre-service teachers' learning during each lesson. The Chalk and Talk lesson was classified as transmissive, or teacher-directed, with a passive learner, which could be considered as having very little constructivist teaching. The Virtual Lab lesson, where pre-service teachers used their laptops to extract information from an online website, was classified as transactional with a greater amount of interaction by the pre-service teacher and some constructivist teaching. The Hovercraft Lesson, where students experienced 'flight' on a home-made hovercraft constructed out of plywood and powered by a leaf blower, was classified as transformational with a kinesthetic component, including a high level of interaction and a greater constructivist and experiential element (Carver, 1996; Bloom, 2006; and Miller, 1990). All $291 \mathrm{~J} / \mathrm{I}$ pre-service teachers in seven different science classes were taught the same lesson during a single week of their Bachelor of Education program. The pre-service teachers' role-played grade 6 students while experiencing the lessons.

A total of 160 surveys were submitted from the possible 291, creating a 55\% return rate of those who participated in the research. This is comparable to the 50\% return rate for online surveys that is considered acceptable by Dillman (2004). The quantitative data were analyzed using Microsoft Excel and the qualitative data, including general comments by pre-service teachers, were analyzed for frequency to support the quantitative findings. A statistical analysis was not completed on the numerical data.

\section{Teaching Styles of the Mini Lessons}

\section{Lesson 1: Chalk and Talk}

The Chalk and Talk lesson was a lecture-style PowerPoint presentation. It included two teacher demonstrations on Bernoulli's principle. It was classified as transmissive in style, as defined by Miller and Seller, because of its Socratic delivery - the candidates were encouraged to sit, listen, take notes, and ask questions (Miller, 1990). The lecture was a practical, traditional method of teaching often used in a classroom setting at the public, secondary school, and university level (Miller, 1990).

\section{Lesson 2: The Virtual Lab}

This lesson required the pre-service teachers to go on-line to a specific website - http://www.ag.ohiostate.edu/ flight/homepage.html and to navigate through the site and complete a worksheet. This activity would cover the required curriculum objectives on flight as an independent learning activity. This was considered to be a transactional style lesson with a 'virtual' or web-based application. This lesson was best described as transactional in nature because it allowed students to interact with the information on a one-to-one basis (Miller \& Seller, 1990). The pre-service teachers may be able to apply their new knowledge to the various problems and interactive demonstrations (Bloom, 2006; Miller \& Seller, 1990; and Seatter, 2003). 
Within this lesson, there was also a degree of constructivism or 'learning by doing' in that the pre-service teachers explored the online webpage by themselves. This could be considered a guided discovery lesson where the content was learned through the guidance of a worksheet in conjunction with the website (Mayer, 2004). The learners would be obtaining new information and developing their knowledge and understanding of the concepts as they navigated through the various pages. Although not specifically indicated within the lesson format, students would often discuss the slides with their neighbour, adding a component of cooperative learning. The integration of technology into teaching has been based on many grounded educational theories, including constructivism and cooperative learning (Kay, 2004 and 2006).

\section{Lesson 3: The Hovercraft Lesson}

The Hovercraft lesson required that the learners be placed in small groups. This allowed for cooperative learning to assist in the development of knowledge and with the application of problem-solving. The groups circulated through four different stations ranging in application of the required curriculum. The stations included a word search whereby vocabulary was based on grade 6 expectations, the history of Hovercrafts, and of other devices that fly, an observation task determining similarities and differences between an in-house built hovercraft, the first hovercraft and those used today; and the final station was an opportunity to interact with and answer questions based on a small, in-house constructed hovercraft. The pre-service teachers would safely experience hovercraft 'flight' by riding on the hovercraft. Due to the construction of the lesson, it was considered more of a transformational style where students had the opportunity to learn the required curriculum and then interact through a variety of different mediums, solving problems while further developing their understanding (Miller \& Seller, 1990). The more "handson" lesson aligns itself with a more constructivist or experiential learning where the students physically and emotionally experience a hovercraft (Carver, 1996). When considering which type of learner, this lesson would suit, it may be reasonable that those learners who are kinesthetic tactile would benefit most (Felder, 1993). However, those who are visual and auditory learners would also find many benefits to this type of lesson since there were components of each (Bloom, 2006, and Miller, 1990).

\section{ANALYSIS}

It was anticipated that each of the teaching styles would have their own unique strengths and weaknesses. The Chalk and Talk lesson is a more traditional type of lesson that is highly effective when considering time restraints and limited resources. The Virtual Lab lesson was thought to be highly effective if technological resources were available and the computer literacy of the students were sufficient. The authors predicted that the students would be most engaged in the Hovercraft lesson because of the high interactive or "hands-on" approach.

The comments regarding advantages and disadvantages of each lesson were reviewed and the most common statements made by the pre-service teachers are listed in Table 1. In general, the Chalk and Talk lesson was considered easier to prepare with more control of information being taught to a large group. It was considered less engaging for some with little interaction within the class. Some advantages noted by pre-service teachers included easier delivery of the same content at one time to students, easier classroom management, ease in preparation, and safer. Some disadvantages listed included that it could be more boring to students, does not engage visual or kinesthetic learners, and there was little active participation.

Table 1: Most Commonly Mentioned Advantages and Disadvantages of the Chalk and Talk Lesson Listed by J/I Pre-service Teachers

\begin{tabular}{|l|l|}
\hline \multicolumn{1}{|c|}{ Advantages of 'Chalk and Talk' } & \multicolumn{1}{c|}{ Disadvantages of 'Chalk and Talk' } \\
\hline - The entire class is presented with the same information and & - Some students can zone out and disengage from the lesson \\
the teacher knows exactly what content has been covered for & - Less engaging \\
testing purposes. & - Can be boring \\
- Easier to get the information out to the students & - May not work for all students \\
- More content taught in less time & - Dry, language based \\
- Easier to maintain classroom management & - Hard for visual learners \\
- Not as many safety issues & - Little active participation \\
- Teacher ease of preparation & - Management - staying on task \\
&
\end{tabular}


General comments made by the pre-service teachers on their surveys concerning this Chalk and Talk lesson are listed in Table 2. It was thought that those who enjoyed the Chalk and Talk lesson probably did so because they may have been taught generally in this method, although it was not preferred by all. Generally, most students felt that this was a successful lesson, but not necessarily engaging, and therefore may not be a lesson that all elementary students would enjoy. There was some familiarity with the lesson presentation style that perhaps made some preservice teachers more comfortable with this delivery style.

Table 2: Some General Comments by Pre-service Teachers about the Chalk and Talk Lesson

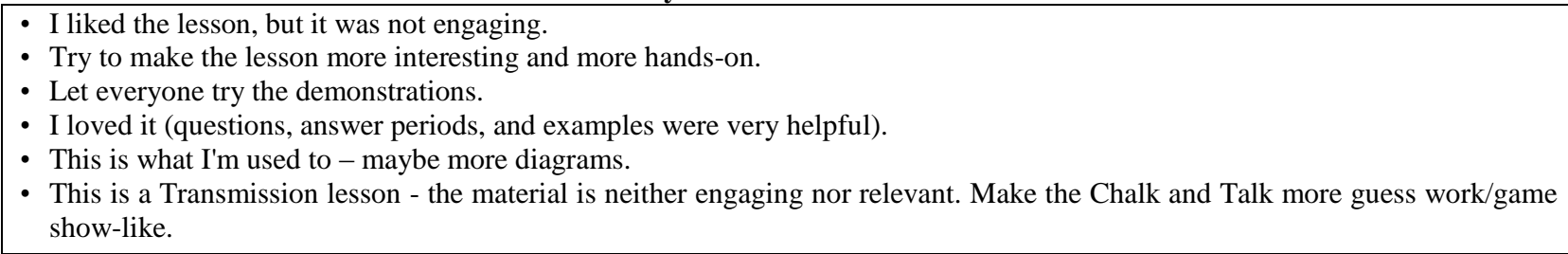

The Virtual Lab lesson involved the pre-service teachers working on their own in completing a worksheet where the answers could be found on the website. Upon completion of the Virtual Lab lesson, students were asked to comment on the advantages and disadvantages of the lesson. The most frequent comments are listed in Table 3. Some pre-service teachers included advantages, such as interesting and engaging interaction with the website, the autonomy of learning at their own pace, teacher has more time to assist challenged students, and the students were actively participating. Some disadvantages included the recognition that a typical grade 6 student may be off task, it could be difficult to determine if learning is occurring, there is a different rate of speed of some students working on the computer, some students are not as literate on the computer as others, and the lack of a full classroom of computers in some schools.

Table 3: Most Commonly Mentioned Advantages and Disadvantages of the Virtual Lab Lesson as Described by the J/I Pre-service Teachers

\begin{tabular}{|l|l|}
\hline \multicolumn{1}{|c|}{ Advantages of 'Virtual Lab' } & \multicolumn{1}{c|}{ Disadvantages of 'Virtual Lab' } \\
\hline - Different & - No tactile understanding of theory \\
- Students are individually applying themselves and & - Do not know if the students are actually learning \\
- Interimenting. & - Students work at different rates of speed on the computer. \\
technology & - Hard to keep track of all students to ensure they are on task \\
- Students can work at their own pace. & - Computer illiterate students \\
- Good integration of technology & - Still isn't that fun \\
- Students are individually applying themselves and & - Staying on task is difficult. \\
experimenting. & - Availability of computers may be a problem. \\
- Students are engaged. & - Some students just look for the answers and they don't read \\
- Set own pace & through the rest of the material. \\
- Teacher has time to assist challenged students & \\
- Students are actively participating in the learning process; \\
good for visual learning very inclusive.
\end{tabular}

The Bachelor of Education program at Nipissing University is a ubiquitous laptop program and this Virtual Lab lesson was possible because all pre-service teachers were required to own their own laptop. There was a mixed reaction on the Virtual Lab lesson, including the limitations of the Internet site used. A few of the general comments are listed in Table 4. Some general comments noted that a few pre-service teachers did not like working on the computer, which was surprising for a laptop program. Some pre-service teachers preferred to read more about the content rather than search for specific content on the accompanied handout. There was a suggestion to have a mark value for completion of the lesson as an incentive for completion. Some pre-service teachers found it engaging and would not change anything. 
Table 4: General Comments of Pre-service Teachers on the Virtual Lab Lesson

- I do not like working with a computer that cannot answer my specific questions.

- Well, I would just have to be allowed to read, explore, and write what I think is important so it doesn't become a competition \& so I don't just search for the answer.

- I found it engaging.

- Have the activity worth something; kids will get bored

- I would circulate the room to make sure that everyone is on task.

- I didn't learn content; I just scanned to fill in blanks.

- I thought it was quite good as-is.

- Tough to ensure that each student has a computer

- I don't think I would change anything.

- Do a more in-depth introduction to direct the learning.

- I found that this activity was just like a PowerPoint presentation.

When examining the qualitative data from the Hovercraft lesson, student reaction was mixed, but yet favorable toward the lesson. Some of the advantages mentioned in the comments refer to the novelty of the experience, the 'hands on' nature of the lesson, and the high degree of interactivity. Many enjoyed the experience of 'flying' on a hovercraft and thought that students would remember the lesson better. Some disadvantages listed include the cost and time to prepare the construction of the hovercraft, the potential safety issues with students, potential behavioural concerns of excited students, and pre-service teachers recognized that the fun or novelty might have more influence than the actual learning that could occur. A summary of the comments that pre-service teachers stated in the survey regarding the advantages and disadvantages are listed in Table 5.

Table 5: Most Commonly Mentioned Advantages and Disadvantages of the Hovercraft Lesson as Described by the J/I Pre-service Teachers

\begin{tabular}{|l|l|}
\hline \multicolumn{1}{|c|}{ Advantages of 'Hovercraft Lesson' } & \multicolumn{1}{c|}{ Disadvantages of 'Hovercraft Lesson' } \\
\hline - Less teacher-directed; students involved less management & - Shy students may be less involved or engaged. \\
issues & $\begin{array}{l}\text { - The material being learned may be over shrouded by the } \\
\text { novelty of the activity. }\end{array}$ \\
- Students are engaged in a scientific experiment. & - Takes time and money to pull it off \\
- Learn hands-on what science can play in everyday life. & - Classroom management could be interesting. \\
- Hands on, combination of activities, can work in small & - Students get carried away; expect it all the time. \\
groups & - Not all students will feel comfortable riding the hovercraft. \\
- It's a lot of fun and different. & - Safety issues \\
- Very interactive fun; students feel involved. & - Did not actually learn why things worked. Not actually \\
- Chteractive easy to get students excited \& interested & learning; just wanting to play and copy answers \\
- This was hands-on to the max. It was a very exciting lesson. & \\
- Hits many learning styles & \\
\hline
\end{tabular}

All general comments were positive toward the hovercraft lesson. A few comments are listed in Table 6, which include how to improve the lesson by using miniature hovercrafts, using it as a motivational tool, and how much the pre-service teachers liked it and would use it in their teaching. The pre-service teachers are starting to see how this would work in a future class and are imagining methods to improve the lesson and adapt it towards their teaching style. These comments may provide insight as to the candidates' perceptions of teaching this lesson within a grade 6 Science classroom.

Table 6: General Comments of Pre-service Teachers on the Hovercraft Lesson

- Less rides; reward students who completed their work

- It was awesome and the kids would love it.

- I would use this.

- Have a website or interactive activity that students can do to learn how hovercrafts work (other than the one where people ride the hovercraft)

- I liked it $100 \%$.

- Add more interesting items.

- Create miniature hovercrafts. 
When examining the quantitative data obtained from the candidate surveys, the responses to the summary questions provide great insight. The first summary question - "Of the three lessons, which one would you like to teach?" - provided expected results. Of those pre-service teachers who completed the survey, $12.41 \%$ would like to teach the Chalk and Talk lesson, 20.44\% would like to teach the Virtual Lab lesson, and 67.15\% would like to teach the Hovercraft lesson, as illustrated in Figure 1.

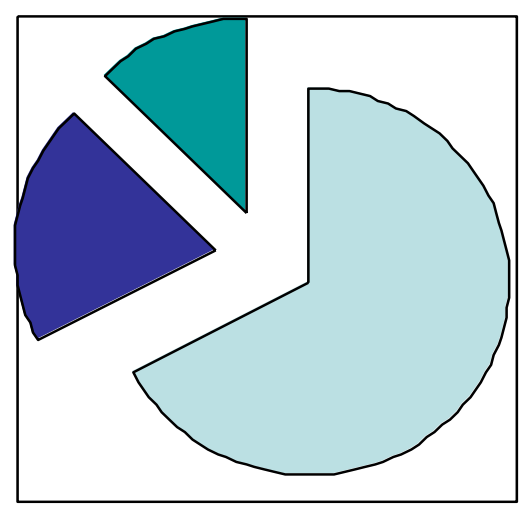

\begin{tabular}{|c|}
\hline$\square$ Hovercraft \\
$67.15 \%$ \\
$\square$ Virtual Lab \\
$20.44 \%$ \\
$\square$ Chalk \& Talk \\
$12.41 \%$ \\
\hline
\end{tabular}

Figure 1: J/I Pre-service teacher candidate survey results for the summary question: "Of the 3 lessons, which one would you like to teach?"

The second summary question asked of the pre-service teacher candidates also gave expected results. Candidates were asked, "Of the three lessons, which one do you think students would learn from the most?". From the data, $18.25 \%$ of the teacher candidates felt students would learn the most from the Chalk and Talk lesson, $19.71 \%$ felt students would learn the most from the Virtual Lab lesson, and $62.04 \%$ felt students would learn the most from the Hovercraft lesson, as illustrated in Figure 2.
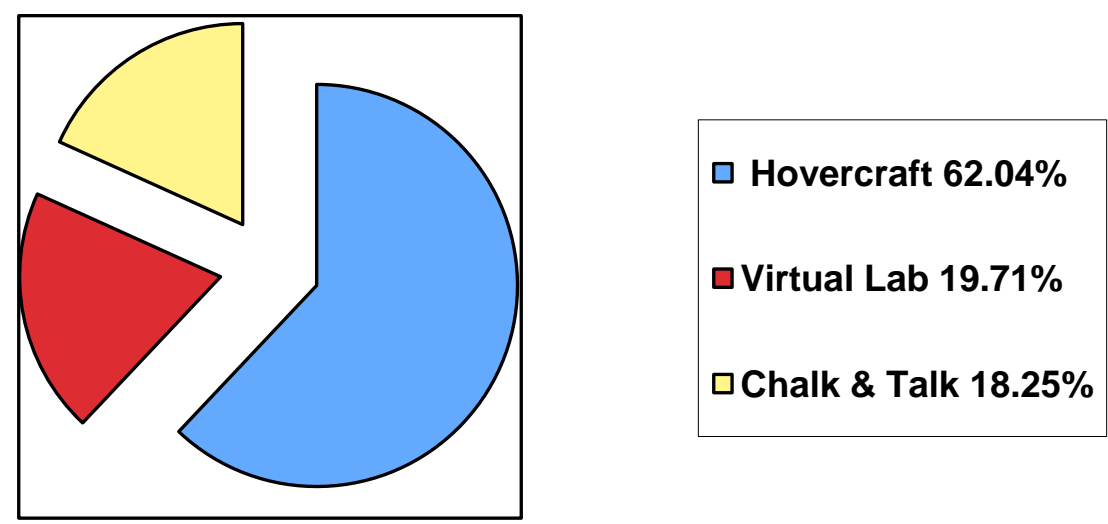

Figure 2: J/I Pre-service Teacher Candidate Survey Results for the Summary Question, “Of the 3 Lessons, Which One Do You Think Students Would Learn the Most From?"

The final summary question was, "Of the three lessons, which one do you think takes the most time in preparation, teaching and evaluation?" As illustrated in Figure 3, survey results were: $8 \%$ of the teacher candidates felt that the Chalk and Talk lesson took the most time to prepare, teach and evaluate; $0.72 \%$ felt it was the Virtual Lab lesson, and $91.3 \%$ felt that the Hovercraft lesson took the most time to prepare, teach and evaluate. 


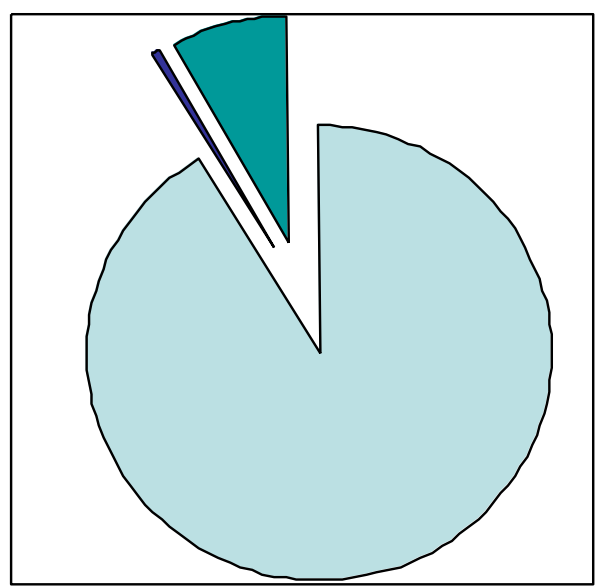

\begin{tabular}{|l|}
\hline$\square$ Hovercraft \\
$91.3 \%$ \\
$\square$ Virtual Lab \\
$0.72 \%$ \\
Chalk \& Talk \\
$7.97 \%$ \\
\hline
\end{tabular}

Figure 3: J/I Pre-service Teachers Survey Results for the Summary Question,:

"Of the 3 Lessons, Which One Do You Think Takes the Most Time in Preparation, Teaching and Evaluation?"

\section{CONCLUSIONS}

Through the survey comments, the pre-service teachers were able to describe numerous advantages and disadvantages in all three types of teaching styles demonstrated in the lessons. When forced to choose which lesson style they would use in their teaching, most pre-service teachers (67\%) chose the Hovercraft lesson, 20\% the Virtual Lab lesson, and $12 \%$ would teach the lecture style - Chalk and Talk lesson. In a real classroom, they would not be restricted to choosing to teach a particular style and could incorporate many teaching styles.

When asked the question, "Of the three lessons, which do you think the students would learn from the most?", the survey results indicate that most of the pre-service teachers (62\%) would learn from the hovercraft, $20 \%$ the Virtual Lab, and 18\% would learn from the Chalk and Talk lesson. These numbers are closely related to the preferred teaching style, suggesting that pre-service teachers appear to prefer to teach in a style that they learned. The small increase (6\%) in regard to the learning occurring in the Chalk and Talk could indicate that some preservice teachers do see the merits in lecture-style teaching as an effective learning style. In looking at the comments to explain a 5\% drop in the expected learning of the Hovercraft lesson, some commented that the hovercraft might be considered more play than learning. A statistical analysis was not done to determine its significance.

When examining the data produced by this survey, some conclusions can be made from the overall impressions of the pre-service teachers concerning each of these lessons. Although the hovercraft lesson took more time to prepare and to teach, the majority of the pre-service teachers felt that they would still teach this lesson. The pre-service teachers would learn more from the 'hands on' Hovercraft lesson than the Virtual Lab or the Chalk and Talk teaching strategies.

The results coincide with the predictions of the faculty in that the pre-service teachers did prefer the hovercraft lesson. The exact percentages were not predicted.

\section{SUMMARY}

The J/I pre-service teachers in the Bachelor of Education program at Nipissing University (2005-2006) participated in faculty-led research examining the perceptions of pre-service teachers experiencing three different teaching strategies in a grade 6 science lesson following the Ontario Ministry of Education Curriculum. The three different teaching strategies were: "Chalk and Talk", "A Virtual Lab", and "A Hovercraft Lesson" incorporating 
increasing levels of constructivism. The pre-service teachers, after participating in the lessons, completed an anonymous survey that rated each of the lessons for strengths and weaknesses, student engagement, and motivation toward the topic. Pre-service teachers also rated the lessons on teaching preference, preparation time, and perceived student engagement within a school setting. Analysis indicated that the pre-service teachers preferred the Hovercraft lesson and were willing to teach it in the future, regardless of the preparation time required or the safety hazards. Most pre-service teachers preferred the Hovercraft lesson, but recognized advantages and disadvantages in all three lessons. Therefore, it could be concluded that when teacher candidates are given the choice of teaching strategies, most would prefer to use a strategy that is very experiential in nature, with high student interaction and engagement, regardless of the preparation time for the teacher, the possible classroom management issues, or evaluation concerns.

\section{AUTHOR INFORMATION}

Dr. Gerald Laronde is an assistant professor, presently teaching Science education in the Faculty of Education at Nipissing University in North Bay, Ontario. He has previously taught science in elementary school, high schools, and at the college level. E-mail: geraldl@ nipissingu.ca. Corresponding author.

Katarin MacLeod is an assistant professor, presently teaching Science education in the Faculty of Education at St. Francis Xavier University, in Antigonish, Nova Scotia. She has previously taught Science at the high school level.

\section{REFERENCES}

1. Bloom, J. W. (2006). Creating a Classroom Community of Young Scientists (2 ed.). New York, NY: Trifolium Books Inc.

2. Carver, R. (1996). Theory for practice: A framework for thinking about experiential education. Journal of Experiential Education, 19(1), 8-13.

3. Creswell, J. W. (2007). Qualitative Inquiry \& Research Design: Choosing Among Five Approaches (2nd ed.). Thousand Oaks, California: Sage Publications.

4. Curry, L. (1990). One critique of the research on learning styles. Educational Leadership 48, 50-56

5. Dillman, D. (2004). Internet surveys: Back to the future. Retrieved February 12, 2008, from www.gse.harvard.edu/hfrp/content/eval/issue27/fall2004.pdf.

6. Kay, R. (2004). Using laptops effectively in higher education. In G. Richards (Ed.), Proceedings of World Conference on E-Learning in Corporate, Government, Healthcare, and Higher Education 2004 (pp. 759764). Chesapeake, VA: AACE.

7. Kay, R. H. (2006). Evaluating strategies used to incorporate technology into preservice education: A review of the literature. Journal of Research on Technology in Education; 38(4), 383.

8. Kolb, D. (1984). Experiential Learning: Experience as the source of learning and development. Englewood Cliffs, NJ: Prentice-Hall

9. Ontario Ministry of Education (1998). The Ontario Science Curriculum: Grades 1 - 8. The Queen's Printer: Toronto.

10. Felder, R. M. (1993). Reaching the Second Tier: Learning and Teaching Styles in College Science Education. Journal of College Science Teaching, 23(5), 286-290.

11. Lortie, D. C. (1975). Schoolteacher: A sociological study. Chicago: University of Chicago Press.

12. Matthew, M. R. (2008). Constructivism in science and mathematics education. Retrieved Feb. 12, 2008 from http://wwwcsi.unian.it/educa/inglese/matthews.html.

13. Miller, J., and Seller, W. (1990). Curriculum: perspectives and practice. Toronto: Copp Clark Pitman, Ltd.

14. Pashler, H.; McDaniel, M.; Rohrer, D.; Bjork, R. (2009). Learning styles: Concept and evidence. Psychological Science in the Public Interest. 9: 105-109.

15. Seatter, C. S. (2003). Constructivist Science Teaching: Intellectual and Strategic Teaching Acts. Interchange, 34(1), 63 - 87. 